\title{
A Influência do Contexto Institucional no Percurso Escolar de Crianças e Adolescentes Institucionalizados
}

\section{The Influence of the Institutional Context on the School Path of Institutionalized Children and Adolescents}

\author{
Laura Isabel Marques Vasconcelos de Almeida*a; Carla Adriana Queiroz ${ }^{\mathrm{a}}$ \\ ${ }^{a}$ Universidade de Cuiabá, Programa de Pós-Graduação Stricto Sensu em Ensino. MT. Brasil. \\ *E-mail: laura.marques@kroton.com.br
}

\begin{abstract}
Resumo
Este trabalho reflete a pesquisa com educadores de uma instituição pública situada no município de Várzea Grande-MT, que recebem crianças e adolescentes que estão sob medida protetiva. A pesquisa tem como objetivo compreender as influências dos contextos social, educativo e familiar, no percurso escolar de crianças e adolescentes institucionalizados, e refletir sobre como os educadores contribuem na reinserção familiar, escolar e cultural dos sujeitos que ali se encontram. Considera-se fundamental o histórico de vida, o percurso escolar e as relações familiares das crianças e adolescentes institucionalizados, no sentido de se compreender o perfil da clientela atendida na instituição e correlacioná-la ao perfil dos profissionais que atuam neste ambiente. Na abordagem metodológica, a pesquisa se utiliza da pesquisa documental e o grupo focal. Como resultado do estudo se espera compreender quais práticas educacionais promovem e estimulam a continuidade dos estudos dos sujeitos institucionalizados, considerando a influência dos profissionais, que atuam na referida instituição como responsáveis pela inserção escolar, familiar e social dos sujeitos.
\end{abstract}

Palavras-chave: Família. Escolarização. Institucionalização.

\begin{abstract}
This work reflects about research with educators from a public institution located in the municipality of Várzea Grande-MT who receive children and adolescents who are under protective measures. The research aims to understand the influences of social, educational and family contexts on the school path of institutionalized children and adolescents and reflect on how educators contribute to the family, school and cultural reintegration of the subjects which are inserted there. It is considered fundamental, the life history, school path and family relationships of institutionalized children and adolescents in order to understand the clientele's profile served in the institution and correlate it with the professionals profile who work in this environment. The methodological research approach uses documentary research and the focus group. As a result of the study, it is expected to understand which educational practices promote and stimulate the continuity of the institutionalized subjects studies, considering the professionals influence who work in that institution as responsible for the subjects'school, family and social insertion.
\end{abstract}

Keywords: Family. Schooling. Institutionalization.

\section{Introdução}

Este artigo apresenta um recorte da reflexão apresentada ao programa de Pós-Graduação em Ensino da Universidade de Cuiabá da linha dois, que tem a finalidade de desenvolver pesquisas voltadas para a compreensão dos fundamentos teóricos e metodológicos da educação escolar. As propostas de pesquisa nesta linha são desenvolvidas no sentido de compreender também as formas de elaboração e aplicação de propostas educativas envolvendo espaços formais e/ou não formais, que será o foco de objeto de estudo.

A pesquisa pretende compreender a influência dos profissionais, que atuam em instituição de acolhimento, na trajetória educativa das crianças e adolescentes acolhidas por essa. Nesta perspectiva se aborda a atuação do Judiciário neste processo, pois não teria como desvencilhar tais temáticas.

Tem-se a intenção de articular os fenômenos recorrentes observados em atuação na área jurídica e pesquisa propriamente dita na instituição de acolhimento, fenômenos estes relatados em documentos formais denominados de estudos psicossociais, que servem de base para tomada de decisão do magistrado. Ressalta-se que tais estudos psicossociais influenciam a tomada de decisão do magistrado no sentido de reinserção da criança e adolescente à família de origem ou institucionalização destes.

Nas atividades laborais, na área jurídica, como psicóloga credenciada desenvolvida junto à Vara da Infância e Adolescência do Fórum da Comarca de Várzea Grande-MT percebe-se que há recorrência de históricos de vida de crianças e adolescentes, que são institucionalizados, ou seja, saem do núcleo familiar por vários motivos, entre estes os maus tratos, negligência e vítima de violência doméstica e/ou sexual, cometido em grande maioria das vezes por familiares, estes são institucionalizados, são colocados em caráter temporário em abrigos ou casas lares, sob a proteção do Estado.

O local no qual está sendo desenvolvida a pesquisa se situa no município de Várzea Grande-MT, intitulada "Casa 
de Passagem" localizada na Avenida Brigadeiro Eduardo Gomes, $\mathrm{n}^{\circ}$ 800, Bairro Planalto Ipiranga II. O estudo visa compreender qual seria a articulação dos contextos sociais, educativos e familiares que permeiam a vida de crianças e adolescentes na construção do conhecimento, em específico, aqueles em condição de institucionalização.

A conhecida "Casa de Passagem" é um local em que prioritariamente ficam institucionalizados adolescentes, que estão sob medida protetiva; tal medida tem por objetivo acolher crianças e adolescentes consideradas vítimas de maus-tratos, abuso sexual e negligência. É uma medida de proteção prescrita pelo Estatuto da Criança e do Adolescente - (BRASIL. Lei $n^{\circ}$ 8.069/90). A casa de passagem tem como função primária acolhimento temporário de adolescentes até que seja concluído o estudo psicossocial e dado direcionamento para estes, que tanto podem ser reintegrados à família de origem quanto podem ser transferidos para outras instituições no Estado e, em último estágio, inseridos em famílias substitutas (adoção).

Os perfis dos adolescentes acolhidos na Casa de Passagem são, em sua grande maioria, composto de indivíduos do sexo masculino e feminino com idades que variam entre 12 a 17 anos anos, contudo, como é uma casa de caráter transitório pode haver em alguns momentos a variação deste perfil.

O perfil da clientela atendida pela instituição é de adolescentes que têm como base familiar a genitora e que para algumas destas o investimento no estudo não é algo importante para a vida, considera-se importante sobreviver economicamente, também são famílias expostas à vulnerabilidade social extrema e alguns a violência doméstica e sexual.

Durante o período em que os adolescentes estão institucionalizados é de responsabilidade dos profissionais e gestores da "Casa de Passagem" conduzir todas as rotinas, inclusive as escolares, que vão desde a matrícula escolar até o acompanhamento médico, se necessário, bem como manter organizadas as pastas documentais de cada adolescente institucionalizado.

Os educadores que compõem a equipe técnica da instituição "Casa de Passagem" têm formação técnica e de nível superior, composta por: psicólogo, assistente social e pedagogo, são funcionários públicos municipais concursados. Contudo, esses profissionais tiveram sua construção subjetiva baseada nas relações sociais, em âmbito familiar e escolar, e a forma com que estes compreendem o mundo e a importância da escolarização podem interferir no resultado do trabalho que desempenham no cotidiano e nas tratativas com adolescentes institucionalizados.

Em contrapartida, também se observa os que se encontram em situação de acolhimento. Para a criança ou adolescentes estar institucionalizado não se tornae uma situação confortável; distante da família ou daqueles que consideram mais próximo, traz para o adolescente uma nova gama de situações e adequações, visto que a condição de estar institucionalizado tem como desdobramento um período de adaptação às novas rotinas, regras e contextos, que são administrados pelos educadores da casa de acolhimento.

Em situações em que crianças e adolescentes estão institucionalizados há total responsabilidade do Estado que tenham seus diretos assistidos, tais como acesso à educação, saúde e segurança. Em relação à instituição que os recebe e estão sob tutela terá que obedecer às regras, incluindo a obrigatoriedade de estar regularmente matriculado e frequentando as aulas. Contudo, é comum que não se adaptem ao ambiente escolar e desenvolvam algum tipo de aprendizado, bem como é perceptível pelos dados previamente analisados durante esta pesquisa, que grande parte dos acolhidos tem um percurso escolar fragmentado, que nem sempre existiu aprendizado e que também não houve incentivo, valorização ou motivação por parte dos familiares em continuar ou promover condições mínimas para que o adolescente continuasse os estudos. No entanto, a instituição denominada "Casa de Passagem" conta com uma equipe técnica para acompanhar os que estão institucionalizados e promover a reinserção social dos assistidos.

\section{Material e Métodos}

A pesquisa tem como objetivo compreender as influências dos contextos social, educativo e familiar no percurso escolar de crianças e adolescentes institucionalizados, contudo o cerne deste estudo é compreender a influência dos profissionais, que atuam na instituição na continuidade do percurso escolar e reinserção no meio social, familiar e cultural do sujeito institucionalizado.

Nesse sentido se considera fundamental levantar o histórico de vida, o percurso escolar e as relações familiares das crianças e adolescentes institucionalizados e se apoia na abordagem metodológica da fenomenologia, no grupo focal e nas fontes documentais.

Segundo Amatuzzi (2009, p.5), a pesquisa fenomenológica é uma forma de pesquisa qualitativa que "designa o estudo do vivido, ou da experiência imediata pré-reflexiva, visando descrever seu significado; ou qualquer estudo que tome o vivido como pista ou método".

A pesquisa desenvolvida na instituição intitulada Casa de Passagem, situada no município de Várzea Grande-MT, conta com a participação de quatro profissionais, sendo: uma psicóloga, um assistente social, uma pedagoga e o gestor da instituição.

O grupo focal é a técnica utilizada para coleta de dados, principalmente, em se tratando de pesquisa qualitativa em Ciências Sociais e Humanas, por se tratar de uma ferramenta que pode ser utilizada com várias finalidades e agregada com outros instrumentos de investigação, como a observação, o questionário ou a entrevista, que podem ser úteis nas análises por triangulação para a comprovação ou refutação de dados. 


\section{Resultados e Discussão}

A proposta deste estudo é refletir sobre o fenômeno específico e observar as condições e percepções que levam um adolescente a ser institucionalizado em uma casa de acolhimento do Estado e a dar continuidade ao percurso escolar, com a possibilidade de receber influência dos profissionais, que atuam no ambiente e na escolarização.

Ao tratar da temática institucionalização de crianças, no Brasil, torna-se necessário considerar o histórico, a origem e objetivos do período colonial de 1500 até 1822, durante o qual o Brasil se estruturou economicamente e politicamente, por meio do vínculo com a metrópole portuguesa. As leis e as ordens para as crianças vinham dessa metrópole e eram aplicadas pelos meios burocráticos dos representantes da corte e da Igreja Católica.

Importantes instituições responsáveis pela administração e ordenação de crianças, no período colonial, eram a Igreja e o Estado, que se uniam no processo de manutenção do poder, articulando a conquista armada com a legitimação religiosa. O cuidado com as crianças índias, segundo Faleiros (2004, p. 2) era realizado pelos padres jesuítas que tinham o objetivo de catequizá-las, batizá-las e incorporá-las ao trabalho. Neste período, foram fundadas casas de recolhimento ou Casas para meninos e meninas índias, contudo tais institucionalizações tinham como objetivo macro o atendimento a economia vigente, pois as crianças eram vistas meramente como mão de obra futura.

Outro fator relevante se tratando de institucionalização de crianças, no Brasil, era a grande mortalidade infantil e, também, como prática social e política, a separação dos filhos de suas próprias mães. As relações sexuais entre senhores e escravas ou índias eram uma prática comum, considerada imoral e ilegítima, ocorrendo um grande número de filhos ilegítimos, contrariando a moral do casamento. Os filhos nascidos fora do casamento, com raras exceções, eram fadados ao abandono. A pobreza também era causa de abandono.

No período colonial, entre as formas de institucionalização da criança e adolescente, no Brasil, a mais duradoura foi a "roda dos expostos". De acordo com Pereira e Costa (2004), o nome roda se refere a um artefato de madeira fixado ao muro ou janela do hospital, no qual era depositada a criança, que ao girar o artefato era conduzida para dentro das dependências internas sem que a identidade de quem ali colocasse o bebê fosse revelada.

A maioria dessas crianças enjeitadas ou expostas era branca ou parda, filhos de brancos ou de brancos e negros. A primeira roda foi criada, em 1726, na Bahia e a última em São Paulo, sendo extinta nos anos cinquenta, conforme Faleiros (2004, p. 3). Essa prática foi extinta definitivamente, em 1950. Durante mais de um século, a roda dos expostos foi praticamente a única instituição de assistência à criança abandonada em todo o Brasil. Nos meados do século XIX, após a Independência do Brasil, a formulação de políticas para a infância se inscreve como uma questão da ordem pública.

Rizzini (2007) aponta que, no Brasil, historicamente, a política de atendimento à infância e ao adolescente em situação de abandono vem sofrendo diversas transformações. A implantação da política de atendimento mudou gradualmente passando do domínio da igreja para entidades filantrópicas até se tornar responsabilidade do Estado.

A Constituição Federal de 1988 já introduzia mudanças nos direitos da Criança e do Adolescente.

É dever da família, da sociedade e do Estado assegurar à criança e ao adolescente, com absoluta prioridade, o direito à vida, à saúde, à alimentação, à educação, ao lazer, à profissionalização, á cultura, á dignidade, ao respeito, à liberdade a convivência familiar e comunitária, além de colocá-los a salvo de toda forma de negligência, discriminação, exploração, violência, crueldade e opressão (BRASIL, 1988).

De acordo com Silva (2004), a partir da Constituição Federal de 1988, houve a formação de diversas associações que se articularam na luta, elaboração e na homologação do Estatuto da Criança e do Adolescente em 1990 - Lei Federal $\mathrm{n}^{\circ} 8.069 / 90$. A partir do ECA, as crianças e os adolescentes passaram de "objetos de tutela" a "sujeitos de direitos e deveres".

Segundo o Levantamento Nacional de Abrigos para Crianças e Adolescentes (SILVA, 2004), cerca de 20 mil crianças e adolescentes abrigados vivem em situação de institucionalização no Brasil, sendo que $87 \%$ desses possuem família e 58\% mantêm vínculo com seus familiares. Uma superficial análise desses dados leva a pensar sobre como anda a qualidade e a construção dos vínculos afetivos dos adolescentes com suas respectivas famílias, quais as percepções que estes possuem deste núcleo familiar e como podem influenciar na continuidade do percurso escolar.

A respeito da família como elemento estrutural e constituinte do ser humano se entende família como "uma forma de organização ou disposição de um número de componentes que se inter-relacionam de maneira específica e recorrente" (WHALEY; WONG, 1989; p. 21). Desse modo, a estrutura familiar se compõe de um conjunto de indivíduos com condições e posições socialmente reconhecidas, com uma interação regular e recorrente.

As configurações familiares sofreram alterações ao longo da história, sendo que até o século IX, as famílias tidas como socialmente aceitáveis eram as tradicionais, compostas por pais e filhos, essa proposta de constituição familiar permaneceu até meados do século XX, quando novas configurações familiares surgiram, advindas de mudanças no contexto socioeconômico da sociedade e pela entrada na mulher no mercado de trabalho.

A família é o primeiro núcleo social que o ser humano faz parte, independente da constituição familiar. $\mathrm{O}$ formato de família ou o ideal mudou ao longo do desenvolvimento da sociedade e do contexto histórico, sendo que não existe atualmente, somente o formato de família tradicional ou 
matrimonial, têm-se outros tipos de famílias na sociedade contemporânea, entre as quais se destacam: informal (formada por meio de uniões estáveis entre casais heterossexuais ou homossexuais); monoparental (formada por qualquer um dos pais); anaparental (Ana - sem; família sem os pais, apenas irmãos), famílias mosaico ou reconstruídas, quando os pais têm filhos e se separam, mas estabelecem novas famílias e ambas as famílias conseguem conviver em harmonia. É importante ressaltar que existem outros tipos de famílias não citados nessa breve descrição.

Minuchin (1990, p.139-142) sobre dinâmica familiar afirma que:

No interior da família, os indivíduos podem constituir subsistemas, formados pela geração, sexo, interesse e função, havendo diferentes níveis de poder, e onde os comportamentos de um membro afetam e influenciam os outros membros. A família como unidade social, enfrenta uma série de tarefas de desenvolvimento, diferindo no nível dos parâmetros culturais, mas possuindo as mesmas raízes universais.

Com intuito de compreensão acerca dos fenômenos, que acontecem nos processos de ensino e aprendizagem com crianças e adolescentes, em situação de acolhimento institucional, faz-se necessário abordar teóricos da Psicologia sócio-histórica e sociointeracionista se tornam importantes para compreensão. Autores como Piaget (2011), Vygotsky (1989) e Wallon (2010), bem como as articulações de suas ideias com a fenomenologia, expressas nas obras de Merleau Ponty (2006), contribuem sobremaneira para se compreender o objeto de estudo. Em contrapartida, a articulação com outros autores que também contribuem para a compreensão do que é ser educador independentemente do local, que atua profissionalmente.

Para Vygotsky (1989), a história da sociedade e o desenvolvimento do homem estão totalmente interligados e inseparáveis. Os mecanismos que os adultos tentam transmitir para as crianças, como hábitos, modos, valores, pensamentos, experiências e cultura, demonstram que ao nascer já mantém constante interação com crianças e adultos, em consequência disso, os processos cognitivos e psicológicos mais complexos vão tomando formas que no início são chamadas de intrapsíquicos, ou seja, partilhados no contato com as pessoas e, na medida em que a criança vai crescendo, os processos acabam por se tornar intrapsíquicos.

Contudo, o completo e individual processo de aprendizagem perpassa pelo viés do afeto e segundo a teoria Walloniana traz grandes contribuições para o entendimento das relações entre educando e educador, além de situar a escola como um meio fundamental no desenvolvimento desses sujeitos.

Wallon (2010, p.117) afirma que: "os domínios funcionais entre os quais se distribui as etapas que a criança percorre, são da afetividade, do ato motor, do conhecimento e da pessoa".

$\mathrm{O}$ objeto da pesquisa é compreender quais seriam as influências que interferem no processo de ensino e aprendizagem e na continuidade dos estudos de crianças e adolescentes institucionalizados. Até que ponto os contextos sociais, familiares, escolares e, principalmente, os institucionais interferem neste percurso. A esse respeito, as ideias centrais da teoria de Piaget (2011) contribuem, considerando que a sua formação é biologia e a variável vinda do plano biológico e social prioriza também os mecanismos de adaptação ao meio. Segundo o autor, o sujeito tem necessidades biológicas de sobrevivência. Para se adaptar ao meio, o indivíduo busca modificar esse meio pela ação e interação com o ambiente.

Nesta perspectiva, Piaget (2011, p.89) afirma que:

Levando em conta, então, esta interação fundamental entre fatores e externos, toda conduta é uma assimilação do dado a esquemas anteriores (assimilação a esquemas hereditários em graus diversos de profundidade) e toda conduta é, ao mesmo tempo, acomodação destes esquemas a situação atual. Daí resulta que a teoria do desenvolvimento apela, necessariamente, para a noção de equilíbrio entre os fatores internos e externos ou, mais em geral, entre a assimilação e a acomodação..

Segundo Piaget (2011), o conhecimento não é algo acabado, estanque e que possa ter um fim, mas uma dimensão que está em constante transformação e movimento pelo sujeito, que por meio de sua ação constrói conhecimentos indispensáveis para sua adaptação ao meio.

Um sujeito não se constitui sozinho, o faz a partir das interações com os outros, com o Mundo e com ele mesmo, e afirma Merleau Ponty (2006, p.5) sobre a percepção de Mundo de um sujeito que:

O mundo está ali antes de qualquer análise que eu possa fazer dele, e seria artificial fazê-lo derivar de uma série de sínteses que ligariam as sensações, depois os aspectos perspectivos do objeto, quando ambos são justamente produtos da análise e não devem ser realizados antes dela. A análise reflexiva acredita seguir em sentido inverso o caminho de uma constituição prévia, e atingir no 'homem interior', como diz santo Agostinho, um poder constituinte que ele sempre foi.

Merleau-Ponty (2006) ainda afirma que é por meio do ato reflexivo que é percebido pelo corpo que se tem a consciência. Não se trata de uma operação do espírito, como entende a tradição, por meio de um fenômeno mental. Dessa forma, a percepção é feita por coisas e de vazios entre tais coisas, podendo se construir por contiguidade (em que a unidade se dá pelo hábito, pela possibilidade da memória preceder a projeção, o que ocorre com que a quantidade de vezes que algo se manifesta em conjunto, ou sucessivamente a outra coisa).

Por se tratar ainda de uma pesquisa em andamento, destaca-se previamente os resultados parciais, contudo, traz algumas reflexões importantes acerca do objeto de estudo. Durante o percurso metodológico foram realizadas reuniões com educadores da instituição com o intento de levantar informações e prepará-los para o grupo focal, bem como as pesquisas documentais nas pastas individuais dos adolescentes institucionalizados. Esta preparação prévia é necessária para 
que se consiga extrair informações mais fidedignas.

Ao realizar as entrevistas e levantamento de informações se conseguiu traçar minimamente o perfil da clientela atendida na instituição e fica evidenciado que se trata de um grupo heterogêneo, em média entre 10 a 15 adolescentes institucionalizados do sexo masculino e feminino.

Uma constatação havia sido percebida durante as entrevistas e na pesquisa documental, que a instituição tem caráter transitório, ou seja, o adolescente permanece neste ambiente, enquanto aguarda decisão judicial sobre qual seria o direcionamento para a sua vida (transferência para outra instituição, reinserção à família ou ainda em família substituta), contudo, alguns permanecem na instituição mais tempo que o legal e apresentam algum tipo de transtorno mental, necessitando de tratamento médico e psicológico, fatores que combinados trazem prejuízos para a continuidade dos estudos.

Diante da situação da permanência de adolescente institucionalizado, além do prazo legal se observa a situação de um sujeito, trata-se de A.G.J., atualmente com 19 (dezenove) anos, que segundo os documentos e estudos psicossociais, tanto produzidos pelos profissionais da Casa de Passagem, quanto os produzidos pela equipe técnica da Vara da Infância e Adolescência de Várzea Grande-MT, o adolescente em questão foi institucionalizado ainda na primeira infância junto com dois irmãos mais velhos na cidade de Cuiabá-MT, no antigo Lar da Criança.

Ao inaugurar a instituição Projeto Vida Nova em Várzea Grande-MT foram transferidos para esta instituição, a genitora era andarilha e usaria substâncias psicoativas e com seu falecimento, os irmãos foram institucionalizados. Os registros apontam indícios de que os irmãos mais velhos do A.G.J permaneceram institucionalizados até completarem 18 anos e, posteriormente, seguiram com a própria vida.

A.G.J permaneceu institucionalizado na cidade de Várzea Grande-MT, por mais de 15 anos, em mais de duas instituições. Ele tem déficit intelectual e sua idade mental não corresponde com a idade cronológica, precisa constantemente de supervisão para organização da vida diária, tem autonomia para cuidados pessoais relacionados à higiene pessoal e rotina, verbaliza fatos e ideias dentro de sua percepção de Mundo, tem irmãos biológicos, mas que naquele momento não conseguiam assumir a responsabilidade sobre o mesmo, por situações adversas.

Durante todo período que o adolescente A.G.J esteve institucionalizado até completar a idade cronológica de 18 anos recebeu atendimento humanizado na instituição referente às necessidades, materiais e médicos. Consta que o processo judicial referente à institucionalização era de responsabilidade da Vara da Infância e Juventude do Fórum de Várzea GrandeMT, mas ao completar maior idade, 18 anos, o processo havia sido transferido para outra Vara dentro do Judiciário e, nesta nova ótica, o magistrado compreendeu que não era necessária tal institucionalização e demandou para que o adolescente A.G.J durante o dia permanecesse em atendimento em uma unidade do CAPS AD situado no município de Várzea Grande-MT, local em que receberia medicação e refeições. A noite deveria se recolher em companhia do irmão biológico.

Inicialmente, esta estratégia de administração da rotina do adolescente A.G.J deu certo, contudo, com passar do tempo esta rotina saiu do controle, o irmão biológico do adolescente A.G.J não conseguiu gerir tal relação com o irmão, visto que não existiam sequer vínculos afetivos entre ambos e a rotina do adolescente mudou drasticamente. Nesse cenário, o adolescente permanecia durante o período diurno sendo acolhido pelos profissionais do CAPS $\mathrm{AD}$ e, no período noturno, passava as noites no terminal de ônibus próximo à unidade do CAPS AD. Segundo informações colhidas junto aos profissionais da Casa de Passagem, o adolescente começou a cometer atos ilícitos para sobreviver e envolvimento com usuários de SPA (Substancia psicoativa).

Até aqui, os dados previamente analisados apontam que em relação aos educadores da Instituição (psicólogo, assistente social e pedagoga) percebe-se que são profissionais com formação superior, são acessíveis e abertos ao diálogo. Todos contribuem de maneira satisfatória com esta pesquisa e durante as entrevistas e várias reuniões fica evidente que esses profissionais se encontram desmotivados em relação ao trabalho e a relação com os adolescentes institucionalizados está desgastada.

\section{Conclusão}

A institucionalização para alguns nem sempre é a solução mais adequada, contudo ao se observar o caso narrado de A.G.J, no período em que esteve institucionalizado teve acesso ao atendimento humanizado, dentro de parâmetros mínimos, teve acesso à educação e conseguiu, considerando suas limitações intelectuais, adquirir certa autonomia, conforme os depoimentos dos educadores da Casa de Passagem, durante o período que esteve sob a responsabilidade da referida Instituição.

Durante sua permanência conseguiam administrar a rotina do adolescente cumprindo as exigências médicas, educacionais e até inserção no mercado de trabalho. A.G.J trabalhava como empacotador em uma rede de supermercado, porém o trabalho não teve continuidade, em função da mudança de ótica oriunda do setor Judiciário que parece ter reduzido a vida deste sujeito, à ilegalidade e invisibilidade social, tal qual sua genitora, uma triste história que se repete.

A pesquisa ainda em andamento reflete, neste artigo, apenas um pequeno recorte de algumas situações envolvendo crianças e adolescentes institucionalizados. A análise empreendida do fenômeno, certamente contribuirá para a compreensão da origem do estudo e, quem sabe fomentar a elaboração de políticas públicas favoráveis no sentido de oferecer condições para que as famílias cuidem do desenvolvimento de seus 
descendentes. Questões relacionadas à vulnerabilidade social, que afetam diretamente crianças e adolescentes, são fatos recorrentes durante toda história do Brasil.

\section{Referências}

AMATUZZI, M. M. Psicologia fenomenológica: uma aproximação teórica humanista. Estud. Psicol., v,26, n.1, 2009, p.93-100, 2009.

BRASIL, Constituição da República Federativa do Brasil. 05 de outubro de 1998.

BRASIL, Estatuto da Criança e do Adolescente. Lei $\mathrm{n}^{\circ}$ 8069, de 13 de julho de 1990.

BRASIL, Nova Lei da Adoção. Lei no 12.010 de 03 de agosto de 2009.

FALEIROS, V.P. Infância e adolescência: trabalhar, educar, assistir, proteger. Rev. Ágora, v.1, n.1 2004.

MERLEAU-PONTY, M. Fenomenologia da percepção. São Paulo: Martins Fontes, 2006.

MINUCHIN, S. Famílias: funcionamento e tratamento. Porto
Alegre: Artes Médicas, 1990.

PEREIRA, J.F.; COSTA, L.F. O ciclo recursivo do abandono. Psicologia.pt. 2004. Disponível em: http://www.psicologia.com. pt/artigos. Acesso em 16 fev. 2020.

PIAGET, J. Seis estudos de Piaget. Rio de Janeiro: Forense Universitária, 2011.

RIZZINI, I. Acolhendo crianças e adolescentes: experiência de promoção de direito à convivência familiar e comunitária no Brasil. São Paulo: Cortez, 2007.

SILVA E.R.A. O perfil da criança e do adolescente nos abrigos pesquisados. In: SILVA, E.R.A. (Coord.). O direito à convivência familiar e comunitária: os abrigos para crianças e adolescentes no Brasil. Brasília, IPEA, 2004. p. 41-69.

WALlON, H. A evolução psicológica da criança: São Paulo: Martins e Fontes, 2010.

VYGOTSKY, L. Formação social da mente. São Paulo: Martins Fontes, 1989.

WHALEY, L.F.; WONG, D. Enfermagem pediátrica: elementos essenciais à intervenção efetiva. Rio de Janeiro: Guanabara Koogan, 1989. 